\title{
Comparisons of Motor Actions and Biomechanical Assessments of Judo Techniques Between Female Weight Categories
}

\author{
by \\ Dany Alexis Sobarzo Soto ${ }^{1}$, Esteban Aedo-Muñoz ${ }^{2}$, Ciro José Brito ${ }^{3}$, \\ Bianca Miarka ${ }^{3,4}$
}

This study aimed to perform motor action and biomechanical analysis of techniques in female judo athletes separated by weight categories of 638 female bouts (103 extra lightweight $<48 \mathrm{~kg}$, 140 half lightweight $48>52 \mathrm{~kg}, 65$ lightweight $52>57 \mathrm{~kg}, 73$ half middleweight $57>63 \mathrm{~kg}, 77$ middleweight $63>70 \mathrm{~kg}, 80$ half heavyweight $70>78 \mathrm{~kg}$ and 60 heavyweight $>78 \mathrm{~kg}$ ). All bouts were analyzed following the phases of approach, gripping, defensive action, attack, also biomechanical analysis of techniques and groundwork was performed $(p \leq .05)$. Results indicated that lightweight athletes presented lower attempts to grip, right collar grip and left collar grip frequencies than other categories. Extra lightweight judokas presented lower right back grip and left back and sleeve grip frequencies as well as lower occurrence of techniques with arm and leg lever scored than half lightweight athletes, while half lightweight athletes demonstrated higher frequency of techniques with waist lever variable scored than lightweight ones. These findings should be considered for training prescription.

Key words: time and motion analysis, biomechanical analysis, task performance and analysis, martial arts, motor control, training.

\section{Introduction}

Notational analysis identifies action patterns, often referred to as 'performance indicators', in competitive situations (Myers et al., 2013). A technical-tactical analysis can help coaches and athletes develop specific training for properly applying the approach, grips, levers and throws during combat (Miarka et al., 2016a, 2016b, 2018). In fact, studies with judo athletes have shown that some of these variables present differentiated frequencies in winners and losers (Miarka et al., 2016b), in different age categories (Miarka et al., 2012, 2014) and gender (SterkowiczPrzybycien et al., 2017). To the best of our knowledge, no studies have compared motor

actions in the approach, gripping, defensive displacement, lever, counterattack and groundwork phases using the seven weight categories of female judo athletes.

During judo combat, motor actions of each combat phase are highly diversified and the relationships between these variables collectively represent an athlete's attack system or fighting style (Miarka et al., 2017). Moreover, the taxonomy of typical judo throwing techniques (Nage-Waza) was created from a didactic requirement to group the techniques using easier systematic classifications under logical criteria following a proto-biomechanical method, and the

\footnotetext{
1 - Escuela de Kinesiología, Facultad de Salud, Magister en Ciencias la Actividad Física y Deportes Aplicadas al Entrenamiento Rehabilitación y Reintegro Deportivo, Universidad Santo Tomás, Puerto Montt, Chile.

2 - Physical Activity, Sport and Health Sciences Laboratory, Universidad de Santiago de Chile, Santiago, Chile.

3 - Physical Education Department, Federal University of Juiz de Fora, Governador Valadares, Brazil.

4 - Postgraduate Program in Physical Education, School of Physical Education and Sports, Department of Fights. Federal University of Rio de Janeiro, Rio de Janeiro, Brazil.
} 
standard techniques were categorized by parts of the Tori's (the athlete who attacks) body which work as a larger contact-point for energy transfer in throwing (i.e. Te-waza = shoulder, arm and hand techniques; Koshi-waza = hip techniques; Ashi-waza = leg techniques; and Sutemi-waza = sacrifice techniques) (Sacripanti, 2012). However, analysis according to biomechanical variables allows coaches to improve the contextualized techniques and to develop muscular strength and power of each execution (Sterkowicz et al., 2013). Therefore, Sacripanti (2012) developed an analysis using the principium of composition of forces, with flight paths and symmetries, a circular path and spherical symmetry, and a helicoidally path with cylindrical symmetry.

Recently, Sterkowicz et al. (2013) reported that techniques based on a force couple were used less frequently $(39.6 \%)$ than the techniques using a physical lever $(60.5 \%)$, despite no differences between the occurrences of scoring techniques in both genders. Despite this important technical analysis using biomechanical classification, until now no differentiations have been made by weight category, which may help coaches understand how athletes' anthropometry influences the levers of techniques performed during judo attacks.

If there are differences between groups, coaches can use the evidence presented herein to elaborate specific training for each weight category. In addition, strategies can be developed which stimulate skill acquisition and at the same time the athlete can use this strategy to neutralize their opponent's strategy. Therefore, the aim of the present study was to analyze all female athletes classified for the 2012 Olympic Games divided into the seven weight categories considering the technical-tactical variables of approach, gripping, defensive actions, attack along with their biomechanical analysis and groundwork.

\section{Methods}

\section{Participants}

The present study considered elite judo athletes from each weight category who qualified for the Olympic Games in 638 competitive bouts separated according to weight divisions (103 extra lightweight $<48 \mathrm{~kg}, 140$ half lightweight $48>52 \mathrm{~kg}$, 65 lightweight $52>57 \mathrm{~kg}, 73$ half middleweight
$57>63 \mathrm{~kg}, 77$ middleweight $63>70 \mathrm{~kg}, 80$ half heavyweight $70>78 \mathrm{~kg}$ and 60 heavyweight $>78 \mathrm{~kg}$ ). All bouts were analyzed considering the motor actions and biomechanical aspects of techniques from 35 international competitions, including the following: the Olympic Games (London 2012), World Championship (Paris 2011), two editions of World Masters (Almaty 2012; Baku 2011), five Grand Slams (Paris 2011-2012; Tokyo 2011; Rio de Janeiro 2011 and Moscow 2011), five Grand Prix (Düsseldorf 2011-2012; Qingdao 2011; Amsterdam 2011; Abu Dhabi 2011), three Continental Competitions (Asian-Uzbekistan 2012; AmericanMontreal 2012, and European-Chelyabinsk 2012) and 19 World Cups (Prague 2011-2012; Oberwart 2011-2012; Bucharest 2011-2012; Jeju 2012; Madrid 2011-2012; Tbilisi 2011-2012; Warsaw 2011; Tallinn 2012, Miami 2012, San Salvador 2012, Apia 2012, Buenos Aires 2012, Lisbon 2012 and Sofia 2012). The free computer version of the VirtualDub Program 1.8.6(2) was used to fragment and edit images and Frami ${ }^{\circledR}$ software was used to conduct the time-motion analysis. The study was previously approved by the local Ethics and Research Committee.

\section{Measures}

Determination of movement with biomechanical and technical-tactical patterns

The approach phase was subdivided into four categories according to the implemented movement pattern, including a right foot forward stance (Migi-shizen-hontai/Migi-hontai), a left foot forward stance (Hidari-shizen-hontai/Hidari-hontai), and a frontal stance (Shizen-hontai/Jigo-hontai) (Muddle et al., 2017). The domain attempt was evaluated by the "tried to grip with contact" or for the "location of the placement of the hands" on the opponent's judo uniform (judogi), such as the collar, sleeve or back, and lateral location, right or left, following a previously validated protocol (Calmet et al., 2010).

The attack phase of combat was characterized by the specific biomechanical principles, which were identified by the type of force couple applied or the length and point of application of the moment arm, as outlined by Sterkowicz et al. (2013). Throwing techniques which employed a force couple were designated as using: an arm lever, an arm/foot lever, trunk/leg lever, or a trunk/arm lever; while techniques described by the moment arm were 
designated as minimal length (applied at the opponent's waist), medium length (applied at the opponent's knee), variable length (below the opponent's waist) or maximal length (applied at the opponent's foot/ankle) (Sacripanti, 2012; Sterkowicz et al., 2013).

The defense in the standing phase was categorized by the manner in which the defending athlete changed his/her body position and orientation, right or left (Tae-sabaki), in response to an attack and by the use of a counter-attack (Miarka et al., 2017). The groundwork phase of combat was determined by the specific actions conducted, including defensive actions, immobilization/pinning techniques (Osae-waza), chokes (Shime-waza) and arm-locks (Kansetsuwaza) (Sacripanti, 2012; Sterkowicz et al., 2013).

Design and Procedures

In order to guarantee ecological validity and to verify the elite status of the sample, competitive bouts were analyzed using several publically available judo video databases, including those provided by the International Judo Federation (IJF) and the International Olympic Committee. Each video had to be of sufficient quality (standard definition 480/60i) and taken from a landscape view of the entire competition area in order to be included. The competitive bouts were evaluated following previously outlined protocols (Miarka et al., 2012). Reliability testing

The reliability measures were assessed through intra-observer and inter-observer testing procedures on motor actions data provided by two experts with more than ten years of judo experience and university degrees in Physical Education. These experts analysed judo matches using FRAMI software. For inter-observer agreement, the first expert analysed 20 performances of athletes, while the second expert analysed the same 20 athletes (Miarka et al., 2011). After this procedure, the second expert performed the intra-observer agreement selecting 10 combats (20 athletes) in randomized order, before repeating the analysis an additional time. The reliability of this software was examined using Cohen's Kappa (Miarka et al., 2017). The following Kappa values and strength of agreement classifications were used from the distribution for each variable: $0.0-0.2$, poor; 0.21 0.40, fair; 0.41-0.60, moderate; 0.61-0.80, substantial; 0.81-10, almost perfect (Miarka et al., 2017).

\section{Statistical Analysis}

Descriptive data are presented as median and mean ( $25^{\text {th }}$ percentile; $75^{\text {th }}$ percentile) values, Kruskal-Wallis followed by Dunn post hoc tests were conducted to compare motor actions and biomechanical analysis of technique frequencies between weight categories. Cohen's $d$ was used to verify effect size and a significance level of $p \leq .05$ was implemented. All analyses were conducted using SPSS 2.0 for Windows.

\section{Results}

The index of Kappa values of combat/pause phases and motor actions verified in the present study were classified as "Almost Perfect" or "Strong" in $100 \%$ of intra-expert comparisons and in $88 \%$ of inter-expert comparisons, with the following inter-expert and intra-expert values: 0.74 and 0.82 for the approach phase, 0.88 and 0.92 for the right foot forward position, 0.80 and 0.87 index for the left foot forward position, 10 and 10 index for the frontal foot position, 0.15 and 0.95 index for trying to grip, 0.45 and 0.96 for the gripping phase, 0.92 and 0.96 for gripping on the right back, 0.40 and 0.93 for gripping on the right back/sleeve, 10 and 10 for gripping on the left back, 0.91 and 10 for gripping on the left back/sleeve, 0.79 and 0.75 for gripping on the right collar, 0.56 and 0.78 for gripping on the right collar/sleeve, 0.21 and 0.72 for gripping on the left collar, 0.43 and 0.93 for gripping on the left collar/sleeve, 0.53 and 0.97 for gripping on the right/left collar, 0.53 and 0.97 for gripping on the right sleeve, 0.57 and 0.92 for gripping on the left sleeve, 10 and 10 for the arm/leg lever, 10 and 10 for the trunk/arm lever, 10 and 10 for the arm lever, 0.62 and 0.67 for the trunk/leg lever, 10 and 10 for the variable length moment arm, 0.63 and 0.95 for the maximal length moment arm, 0.90 and 10 for the medium length moment arm, 10 and 10 for the minimal length moment arm, 0.84 and 0.90 for the defensive phase, 0.82 and 0.82 for use of counter-attacks, 0.74 and 0.77 for use of Tae-sabaki to the right, 0.60 and 0.77 for use of Tae-sabaki to the left, 0.90 and 0.97 for the groundwork combat phase, 10 and 10 for pinning techniques (Osae-waza), 10 and 10 for armlock techniques (Kansetsu-waza), 10 and 10 for choking techniques (Shime-waza), and 0.91 and 
0.99 for the pause combat phase.

Figure 1 demonstrates the frequencies of combat phases by combat.

When comparing the approach frequencies $\left(X^{2}=22.496 ; \mathrm{df}=6, p \leq .001\right)$, the half lightweight category demonstrated higher approach attempts than lightweight bouts $(p \leq$ $.001,95 \%$ CI $2.4 ; 13.9)$, half heavyweight $(p=.006$, $95 \% \mathrm{CI} 1 ; 11.8)$ and heavyweight $(p \leq .001,95 \% \mathrm{CI}$ $2.5 ; 15.5)$ categories.

For the total attack analysis $\left(X^{2}=14.983\right.$; $\mathrm{df}=6, p=.020)$, heavyweight presented lower frequency than half lightweight $(p=.025,95 \% \mathrm{CI}$ $7.7 ;-0.3)$, half middleweight ( $p=.002,95 \% \mathrm{CI}-9.4$; 1.2), middleweight ( $p=.037,95 \%$ CI $-8.3 ;-0.1)$.

No effects were observed for total frequencies of gripping $(p=0.303)$, defensive actions $(p=.070)$ or groundwork frequencies $(p=$ 0.36).

Table 1 demonstrates a descriptive analysis of the approach of motor actions.

Regarding approach phase actions, by analysing the Hidari-shizen-hontai/Hidari-hontai ( $\mathrm{X}^{2}$ $=59.107 ; \mathrm{df}=6, p \leq .001)$, half lightweight demonstrated higher attempts than extra lightweight ( $p \leq .001,95 \%$ CI 1 to 5.1 ), lightweight $(p \leq .001,95 \%$ CI $1.6 ; 6.7)$, half middleweight $(p=$ $.006,95 \%$ CI $0.5 ; 5.4)$ and heavyweight $(p=.044$, $95 \%$ CI $0.4 ; 5.8)$ groups. No effects were observed when comparing weight categories in Migi-shizenhontai/Migi-hontai frequencies $(p=0.52)$, or in Shizen-hontai/Jigo-hontai frequencies $(p=0.164)$. Table 3 demonstrates the motor actions analysis of attempts to dominate the opponent.

For gripping attempt frequencies, a significant difference was observed between categories $\left(X^{2}=26.433 ; \mathrm{df}=6, p \leq .001\right)$, in which lightweight presented lower values than extra lightweight $(p=.039,95 \% \mathrm{CI}-6.2 ;-0.1)$, half lightweight $(p \leq .001,95 \% \mathrm{CI}-7.8 ;-2)$, half middleweight $(p \leq .001,95 \% \mathrm{CI}-8.4 ;-1.8)$ and the middleweight group ( $p=.028,95 \% \mathrm{CI}-6.7 ;-0.2)$, while the heavyweight category demonstrated lower attempts than half lightweight $(p=.021$, $95 \% \mathrm{CI}-6.8 ;-0.3)$ and half middleweight group ( $p=$ $.036,95 \% \mathrm{CI}-7.4 ;-0.12)$. Regarding gripping actions, when comparing the right back sleeve grip, statistical analysis demonstrated significant differences $\left(X^{2}=29.853 ; \mathrm{df}=6, p \leq .001\right)$, in which the extra lightweight group demonstrated lower values than half lightweight $(p=.007,95 \%$ CI -1.7 ;
0.1 ) and half middleweight ( $p=.028,95 \%$ CI -1.8; $0.1)$. When comparing left back sleeve grip frequencies $\left(X^{2}=16.929 ; \mathrm{df}=6, p=.01\right)$, the extra lightweight category demonstrated higher values than half lightweight ( $p=.007,95 \%$ CI $0.1 ; 1.6)$. For the right collar sleeve grip $\left(X^{2}=39.654 ; \mathrm{df}=6, p \leq\right.$ $.001)$, the lightweight group demonstrated lower values than half lightweight ( $p=.003,95 \%$ CI -3.1; $0.4)$ middleweight $(p=.003,95 \% \mathrm{CI}-3.5 ;-0.4)$ and half heavyweight ( $p=.011,95 \% \mathrm{CI}-3.3 ;-0.2)$.

Statistical analysis demonstrated significant differences between right and left collar grip frequencies $\left(X^{2}=48.748\right.$; $\mathrm{df}=6, p \leq$ $.001)$, lightweight demonstrated higher values than extra lightweight ( $p \leq .001,95 \%$ CI $1 ; 4)$, half lightweight $(p \leq .001, \quad 95 \% \mathrm{CI} \quad 0.6 ; \quad 3.5)$, middleweight $(p=.01,95 \% \mathrm{CI} 0.3 ; 3.5)$, half heavyweight $(p \leq .001,95 \% \mathrm{CI} 0.6 ; 3.8)$ and heavyweight ( $p=.037,95 \% \mathrm{CI} 0.1 ; 3.7)$. When right and left sleeve grip frequencies were compared $\left(X^{2}=31.100 ; \mathrm{df}=6, p \leq .001\right)$, the half lightweight category demonstrated higher values than the heavyweight category ( $p=.016,95 \%$ CI $0.2 ; 4.6)$. No effects were observed for the left back ( $p=$ $0.167)$, right back $(p=0.325)$, left collar sleeve $(p=$ $.061)$, right sleeve $(p=0.316)$, right collar $(p=$ $0.369)$, left sleeve $(p=.071)$, or left collar $(p=$ 0.136). Table 4 demonstrates technical biomechanical analysis of attempts and scored actions.

For technical biomechanical analysis, differences between categories were observed when comparing the techniques with the arm and leg lever scored $\left(X^{2}=15.703 ; \mathrm{df}=6, p=.015\right)$, in which the extra lightweight category demonstrated higher values than half lightweight ( $p=.016,95 \%$ CI $-0.2 ;-.0)$. When comparing the frequency of techniques with the waist lever variable scored $\left(X^{2}=14.378 ; \mathrm{df}=6, p=.026\right)$, the half lightweight category demonstrated higher values than lightweight $(p=.021,95 \%$ CI -0.1 ; 2.47).

Significant differences were observed when comparing the frequency of techniques with the maleolo lever attempted $\left(X^{2}=31.706 ; \mathrm{df}=6, p\right.$ $\leq .001$ ), in which the half middleweight group demonstrated higher attempts than half heavyweight $(p=.047,95 \% \mathrm{CI} .0 ; 1.4)$ or heavyweight $(p=.049,95 \% \mathrm{CI} .0 ; 1.6)$. No effects were observed for the arm lever attempted ( $p=$ 0.259), arm and leg lever torque attempted 
( $p=0.314)$, waist lever variable attempts $(p=.097)$, minimum lever attempted $(p=0.301)$, trunk and leg lever attempts $(p=0.456)$, trunk leg lever scored $(p=.083)$ or maleolo lever scored $(p=0.232)$ comparisons. Table 5 shows the defensive and groundwork actions between weight categories.

Significant differences were observed when comparing the frequency of left Tae-sabaki $\left(X^{2}=\right.$ 37.723; $\mathrm{df}=6, p \leq .001)$, where the half lightweight group demonstrated lower values than heavyweight ( $p=.05,95 \% \mathrm{CI} .0 ; 1.6)$. No effects were observed for right Tae-sabaki $(p=0.287)$ or counterattack $(p=1)$. Regarding groundwork actions, inferential analysis showed significant differences when comparing the pause frequency $\left(X^{2}=23.333 ; \mathrm{df}=6, p \leq .001\right)$, in which the half lightweight category demonstrated higher frequencies than the lightweight $(p=.01,95 \% \mathrm{CI}$ $0.4 ; 5.9)$ and heavyweight categories $(p=.028$, $95 \%$ CI $0.2 ; 6.3)$. No effects were observed when compared Kanzetsu-waza $(p=1)$, the defensive position on the ground ( $p=0.199)$, Osae-waza ( $p=$ $0.24)$ and Shime-waza $(p=0.23)$.

\section{Table 1}

Approach motor actions in all female weight categories.

\begin{tabular}{cllllllll}
\hline \multicolumn{1}{c}{ Approach phase positions } & EL & HL & L & HM & M & HH & H \\
\cline { 1 - 4 } Migi-shizen-hontai/Migi-hontai & $5(.0 ; 11)$ & $2(.0 ; 9)^{\mathrm{a}}$ & $5(1 ; 9)$ & $3(.0 ; 11)$ & $2(.0 ; 6)$ & $1(.0 ; 7)$ & $1(.0 ; 6)$ \\
Hidari-shizen-hontai/Hidari-hontai & $.0(.0 ; 4)$ & $2(.0 ; 1)^{\mathrm{b}}$ & $.0(.0 ; 1.5)$ & $.0(.0 ; 4)$ & $1(.0 ; 7)$ & $1(.0 ; 7.8)$ & $1(.0 ; 6)$ \\
Shizen-hontai/Jigo-hontai & $1(.0 ; 5)$ & $1(.0 ; 3)$ & $1(.0 ; 3.5)$ & $1(.0 ; 3)$ & $1(.0 ; 3.8)$ & $1(.0 ; 2)$ & $.0(.0 ; 2)$ \\
\hline
\end{tabular}

Note: $\mu\left(1^{o} ; 3^{\circ}\right)-$ median $\left(25^{\circ} ; 75^{\circ}\right.$ percentiles). EL = Extra Lightweight; HL = Half Lightweight;

$L=$ Lightweight; $H M=$ Half Middleweight; $M=$ Middleweight; $H H=$ Half Heavyweight;

$H=$ Heavyweight. ${ }^{a} p \leq .006$ for this weight category vs. half heavyweight and heavyweight; ${ }^{b} p \leq .044$ for this weight category vs. all, except half heavyweight.

Table 2

Motor actions analysis of attempts to dominate the opponent in all female weight categories.

\begin{tabular}{|c|c|c|c|c|c|c|c|}
\hline Gripping & EL & HL & $\mathbf{L}$ & HM & $\mathbf{M}$ & $\mathbf{H H}$ & $\mathbf{H}$ \\
\hline Gripping attempts & $\begin{array}{l}9 \\
(5 ; 14)\end{array}$ & $1(6 ; 16.8)$ & $6(2.5 ; 1)^{\mathrm{a}}$ & $11(5 ; 16)$ & $1(6 ; 13)$ & $8(3 ; 13)$ & $7(3 ; 12)^{\mathrm{b}}$ \\
\hline Right back & $.0(.0 ; .0)$ & $.0(.0 ; .0)$ & $.0(.0 ; .0)$ & $.0(.0 ; .0)$ & $.0(.0 ; .0)$ & $.0(.0 ; .0)$ & $.0(.0 ; .0)$ \\
\hline Right back sleeve & $.0(.0 ; .0)^{\mathrm{b}}$ & $.0(.0 ; 2)$ & $.0(.0 ; .1)$ & $.0(.0 ; 1)$ & $.0(.0 ; 1)$ & $.0(.0 ; 1)$ & $.0(.0 ; .1)$ \\
\hline Left back & $.0(.0 ; .0)$ & $.0(.0 ; .0)$ & $.0(.0 ; .0)$ & $.0(.0 ; .0)$ & $.0(.0 ; .0)$ & $.0(.0 ; .0)$ & $.0(.0 ; .0)$ \\
\hline Left back sleeve & $.0(.0 ; 1)^{c}$ & $.0(.0 ; 1.1)$ & $.0(.0 ; 2)$ & $.0(.0 ; 2)$ & $.0(.0 ; 1)$ & $.0(.0 ; 1)$ & $.0(.0 ; 1)$ \\
\hline Right collar & $.0(.0 ; 3)$ & $.0(.0 ; 4)$ & $.0(.0 ; 1.5)^{\mathrm{e}}$ & $.0(.0 ; 3)$ & $.0(.0 ; 5)$ & $.0(.0 ; 4)$ & $.0(.0 ; 4)$ \\
\hline Right collar sleeve & $.0(.0 ; 2)$ & $1(.0 ; 4)$ & $.0(.0 ; 1)^{\mathrm{d}}$ & $1(.0 ; 3)$ & $1(.0 ; 4)$ & $1(.0 ; 4)$ & $1(.0 ; 2)$ \\
\hline Left collar & $1(.0 ; 3)$ & $2(.0 ; 6.8)$ & $1(.0 ; 4)^{\mathrm{e}}$ & $2(.0 ; 5)$ & $2(1 ; 6)$ & $2(.0 ; 5)$ & $2(.0 ; 5)$ \\
\hline Left collar sleeve & $2(.0 ; 6)$ & $1(.0 ; 4)$ & $3(1 ; 6)$ & $2(.0 ; 6)$ & $1(.0 ; 5)$ & $.5(.0 ; 4)$ & $1(.0 ; 4)$ \\
\hline Collar collar & $.0(.0 ; 1)$ & $.0(.0 ; 1)$ & $.0(.0 ; 2.5)$ & $1(.0 ; 2)$ & $.5(.0 ; 2)$ & $.0(.0 ; 2)$ & $.0(.0 ; 2)$ \\
\hline Right sleeve & $.0(.0 ; 1)$ & $.0(.0 ; 1)^{\mathrm{f}}$ & $.0(.0 ; 1)$ & $.0(.0 ; 1)$ & $.0(.0 ; 1)$ & $.0(.0 ; 1)$ & $.0(.0 ; 1)$ \\
\hline Left sleeve & $.0(.0 ; 1)$ & $.0(.0 ; 2)^{\mathrm{f}}$ & $.0(.0 ; 1)$ & $.0(.0 ; 1)$ & $.0(.0 ; 1)$ & $.0(.0 ; 1)$ & $.0(.0 ; 1)$ \\
\hline Sleeve sleeve & $2(.0 ; 6)$ & $2(.0 ; 4)$ & $1(.0 ; 4)$ & $1(.0 ; 3)$ & $1(.0 ; 4)$ & $1(.0 ; 3)$ & $.0(.0 ; 2)$ \\
\hline
\end{tabular}

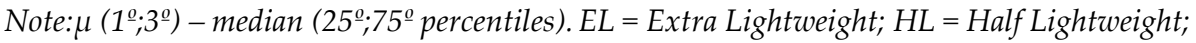

$L=$ Lightweight; $H M=$ Half Middleweight; $M=$ Middleweight; $H H=$ Half Heavyweight;

$H=$ Heavyweight. ${ }^{a} p \leq .006$ for this weight category vs. extra-lightweight, half lightweight, half middleweight and middleweight; ${ }^{b} p \leq .028$ for this weight category vs. half lightweight and half middleweight; ${ }^{c} p=.007$ for this weight category vs. half lightweight; ${ }^{d} p \leq .011$ for this weight category vs. half lightweight, middleweight and half heavyweight; ${ }^{e} p \leq .037$ for this weight category vs. all except half middleweight; $f p=.016$ for this weight category vs. heavyweight. 
Table 3

Biomechanical analysis of attempts and scored attacks in all female weight categories.

\begin{tabular}{|c|c|c|c|c|c|c|c|}
\hline Attacks analysis & EL & HL & $\mathbf{L}$ & HM & $\mathbf{M}$ & HH & $\mathbf{H}$ \\
\hline Arm lever & $.0(.0 ; .0)$ & $.0(.0 ; .0)$ & $.0(.0 ; .0)$ & $.0(.0 ; .0)$ & $.0(.0 ; .0)$ & $.0(.0 ; .0)$ & $.0(.0 ; .0)$ \\
\hline Arm and leg lever & $2(.0 ; 4)$ & $2(1 ; 5)$ & $2(1 ; 6.5)$ & $2(.0 ; 5)$ & $2(.0 ; 6)$ & $3(1 ; 6)$ & $1(.0 ; 4)$ \\
\hline Arm and leg lever with score & $.1(.0 ; 0.5)^{\mathrm{b}}$ & $.0(.0 ; .0)$ & $.0(.0 ; .0)$ & $.0(.0 ; .0)$ & $.0(.0 ; .0)$ & $.0(.0 ; .0)$ & $.0(.0 ; .0)$ \\
\hline Minimum lever & $.0(.0 ; .0)$ & $.0(.0 ; 1)$ & $.0(.0 ; .0)$ & $.0(.0 ; 010)$ & $.0(.0 ; 1)$ & $.0(.0 ; 1)$ & $.0(.0 ; .0)$ \\
\hline Trunk leg lever & $1(.0 ; 3)$ & $1(.0 ; 3)$ & $1(.0 ; 2)$ & $1(.0 ; 3)$ & $1(.0 ; 3.8)$ & $1(.0 ; 4)$ & $.0(.0 ; 2)$ \\
\hline Trunk leg lever with score & $.0(.0 ; .0)$ & $.0(.0 ; .0)$ & $.0(.0 ; .0)$ & $.0(.0 ; .0)$ & $.0(.0 ; .0)$ & $.0(.0 ; .0)$ & $.0(.0 ; .0)$ \\
\hline Waist lever variable & $1(.0 ; 3)$ & $1(.0 ; 3)$ & $.0(.0 ; 2)$ & $1(.0 ; 3)$ & $1(.0 ; 3)$ & $1(.0 ; 3)$ & $1(.0 ; 3)$ \\
\hline Waist lever variable with score & $.0(.0 ; .0)$ & $.1(.0 ; 0.5)^{c}$ & $.0(.0 ; .0)$ & $.0(.0 ; .0)$ & $.0(.0 ; .0)$ & $.0(.0 ; .0)$ & $.0(.0 ; .0)$ \\
\hline Maleolo lever & $.0(.0 ; 1)$ & $.0(.0 ; 1)$ & $.0(.0 ; 1)$ & $.0(.0 ; 2)^{\mathrm{d}}$ & $.0(.0 ; 1)$ & $.0(.0 ; 1)$ & $.0(.0 ; 1)$ \\
\hline Maleolo lever with score & $.0(.0 ; .0)$ & $.0(.0 ; .0)$ & $.0(.0 ; .0)$ & $.0(.0 ; .0)$ & $.0(.0 ; .0)$ & $.0(.0 ; .0)$ & $.0(.0 ; .0)$ \\
\hline
\end{tabular}

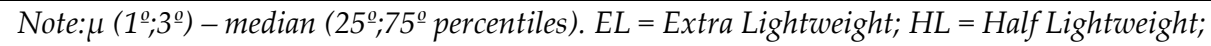

$L=$ Lightweight; HM = Half Middleweight; $M=$ Middleweight; $H H=$ Half Heavyweight;

$H=$ Heavyweight. " $p \leq .025$ for this weight category vs. half lightweight, half middleweight and middleweight; ${ }^{b} p=.016$ for this weight category vs. half lightweight; ${ }^{c} p=.021$ for this weight category vs. lightweight; ${ }^{d} p \leq$ .049 for this weight category vs. half heavyweight and heavyweight.

Table 4

Defensive and groundwork actions in all female weight categories.

\begin{tabular}{llllllll}
\hline Defense & EL & HL & L & HM & M & HH & H \\
\hline Counterattack & $.0(.0 ; 1)$ & $.0(.0 ; 0.8)$ & $.0(.0 ; 1)$ & $.0(.0 ; 1)$ & $.0(.0 ; 1)$ & $.0(.0 ; 1)$ & $.0(.0 ; .0)$ \\
Right Tae-Sabaki & $1(.0 ; 2)$ & $1.5(.0 ; 3)$ & $1(.0 ; 3)$ & $1(.0 ; 3)$ & $2(1 ; 4)$ & $1(.0 ; 3)$ & $1(.0 ; 3)$ \\
Left Tae-Sabaki & $1(.0 ; 3)$ & $2(1 ; 4)^{\mathrm{a}}$ & $1(.0 ; 3)$ & $1(.0 ; 3)$ & $2(1 ; 4)$ & $2(.0 ; 3)$ & $1(.0 ; 2)$ \\
Osae-waza & $.0(.0 ; .0)$ & $.0(.0 ; .0)$ & $.0(.0 ; .0)$ & $.0(.0 ; .0)$ & $.0(.0 ; .0)$ & $.0(.0 ; .0)$ & $.0(.0 ; .0)$ \\
Kansetsu-waza & $.0(.0 ; .0)$ & $.0(.0 ; .0)$ & $.0(.0 ; .0)$ & $.0(.0 ; .0)$ & $.0(.0 ; .0)$ & $.0(.0 ; .0)$ & $.0(.0 ; .0)$ \\
Shime-waza & $.0(.0 ; .0)$ & $.0(.0 ; .0)$ & $.0(.0 ; .0)$ & $.0(.0 ; .0)$ & $.0(.0 ; .0)$ & $.0(.0 ; .0)$ & $.0(.0 ; .0)$ \\
Passive position & $5(3 ; 1.0)$ & $6(3 ; 1.0)^{\mathrm{b}}$ & $4(2 ; 8)$ & $6(3 ; 1.0)$ & $4.5(2 ; 8.8)$ & $5(2 ; 8.8)$ & $3(2 ; 8)$ \\
\hline
\end{tabular}

$\mu\left(1^{\circ} ; 3^{\circ}\right)-$ median $\left(25^{\circ} ; 75^{o}\right.$ percentiles). EL = Extra Lightweight; HL = Half Lightweight;

$L=$ Lightweight $H M=$ Half Middleweight; $M=$ Middleweight; $H H=$ Half Heavyweight;

$H=$ Heavyweight. ${ }^{a} p=.05$ for this weight category vs. heavyweight; ${ }^{b} p \leq .028$ for this weight category vs.

lightweight and heavyweight.
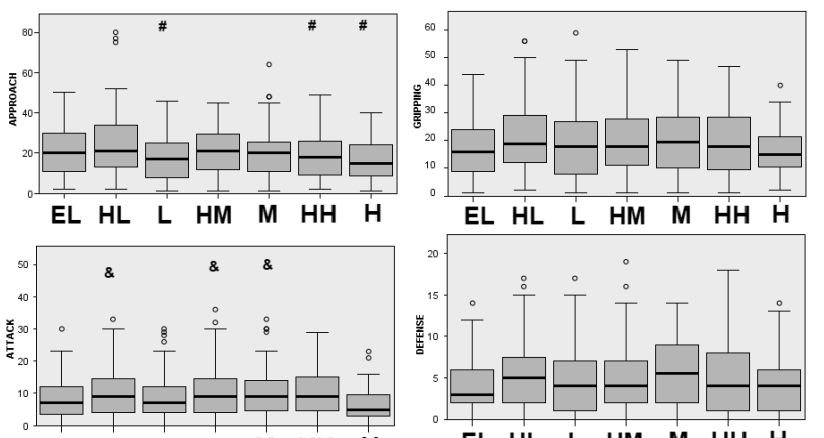

EL HL L HM M HH H
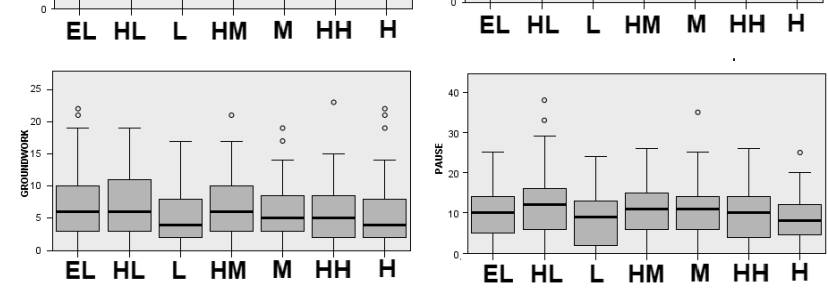

\section{Figure 1}

Box-plot of combat phases frequencies

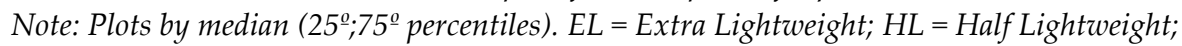

$L=$ Lightweight; HM = Half Middleweight; $M=$ Middleweight; $H H=$ Half Heavyweight;

$H=$ Heavyweight. \# = significant difference when compared with the half-lightweight category; $\mathcal{E}=$ significant difference when compared with the heavyweight category, $p \leq .05$ 


\section{Discussion}

Studies with technical-tactical analysis enable practical application because the results can be used by coaches to prepare specific training aiming towards a specific category in which the athlete competes (Bartlett, 2001). In this sense, some studies have specifically investigated technical-tactical actions in judo athletes (Miarka et al., 2011, 2012, 2014, 2016a, 2016b). However, studies performed so far have not analyzed separately the actions in the seven female weight categories. The main results of the present study indicated that the half lightweight category showed higher approach attempts and Hidarishizen-hontai/Hidari-hontai. The lightweight group presented lower gripping attempt frequencies. The extra lightweight category presented lower values for the right and left back sleeve grip. The lightweight group presented a lower right and left collar grip, while the heavyweight group presented lower total attack frequency. The lightweight category demonstrated higher arm and leg lever scored values, while the half lightweight group demonstrated lower values of left Tae-sabaki. Regarding the main biomechanical lever differences to apply attacks, the extra lightweight group demonstrated higher frequency of techniques with the arm and leg lever scored than the half lightweight, while the half lightweight group demonstrated higher frequency of techniques with the waist lever variable scored than lightweight. The half middleweight category demonstrated higher frequency of techniques with the maleolo lever than the half heavyweight and heavyweight groups. For groundwork actions, the half lightweight category demonstrated higher pause frequencies.

The technical-tactical analysis in judo allows to structure specific training that simulates competitive demands (Marcon et al., 2010), thus the results shown herein can be used by coaches to prepare the athletes to compete at the international level, focusing on the specific actions of their weight category.

The approach and gripping actions are essential for efficient application of throws, as an athlete who does not take the initiative in the handgrip tends to have difficulties dominating their opponent (Miarka et al., 2016). Coaches consider that taking the initiative is a factor which puts the athlete at an advantage (Calmet et al.,
2010), therefore specific sessions are designed to approach and grip with speed and in position to grip the opponent's kimono. Del Vecchio et al. (2014) state that specific information about the approach and gripping is very important for coaches to incorporate into training to adjust and enhance the movements which result in specific tactical acquisition.

Miarka et al. (2016b) observed that winners in competitions of the international Judo Federation and the Olympic Games had a lower approach time and higher gripping frequency. Our results indicated that differentiated attention should be directed to the half lightweight category, since athletes in this category tended to make left defensive movements and presented a lower frequency of right defensive actions, so that specific tactics can be elaborated for athletes in this category to anticipate the movements of their opponents. Since the lightweight and heavyweight athletes have a lower handgrip frequency, it is recommended that higher attention be paid to movements that may eliminate the gripping advantage of the opponents for this group of athletes.

In order to dominate an opponent it is necessary to be incisive in the approach and gripping, and choose a gripping variation which gives an advantage, since the athlete generally tends to apply the gripping pattern which enables a biomechanical advantage to apply the athlete's favorite throwing techniques (SterkowiczPrzybycien et al., 2017). The approach and gripping phases are critical to high level performance, as Calmet et al. (2010) observed that experienced athletes performed those phases with high speed and less movements when compared to beginners and intermediates.

Biomechanical aspects seem to determine the type and preferred gripping, since athletes in lighter categories (possibly smaller in stature) least apply back gripping. Special attention should be directed to lightweight athletes who present higher prevalence of left collar sleeve grips. Specific training can bring benefits to athletes as long as they can perform the preferred actions, as Miarka et al. (2016b) noted experienced athletes dominated more tasks and were able to perform complex movement patterns in less time compared to beginners. In addition, strategies should be created to block the opponent's initial 
attempt, because international high-level athletes assume opposition when they do not get an advantage at first contact with the opponent's kimono (Calmet et al., 2010). Another aspect to be highlighted is the lower gripping variation in all categories. In a previous study, SterkowiczPrzybycien et al. (2017) found that female athletes tended to present a single gripping pattern, and while those data can be partially confirmed in the present study, this fact may be important in this combat phase and deserves more consideration by coaches.

Our results partially corroborate the work presented by Miarka et al. (2012), in which the highest frequency of attacks presented by female athletes included ashi-waza (arm and leg lever) tewaza (arm lever), and koshi-waza (waist lever variable lever). In contrast to the present study, the study by Miarka et al. (2012) was performed with athletes of different ages (pre-cadet to senior). The lower frequency of actions in groundwork combat is emphasized in the present study, as most of the actions were generally found to be mostly defensive, thus coaches may ideally focus on specific training to increase the advantage of athletes due to the training aspect not being adequately explored in all weight categories.

Miarka et al. (2016b) observed that Olympic female champions presented higher volume of groundwork actions. The study's results are limited to observational technicaltactical and biomechanical analysis of combat; however, we acknowledge that this technique does not enable measuring biomechanical performance, which should be considered for training prescription. The present results encourage coaches to use performance analysis, helping female athletes in their weight categories. For instance, our findings indicated that lightweights presented lower attempts to grip, while middle female athletes demonstrated a higher frequency of techniques with the waist lever variable scored than the lightweight category. Such information as well as other particulars may assist athletes in improving their skills, helping them become stronger, and fight better. Knowledge about female judo is scarce, and therefore athletes depend on coaches to observe them during practice and championships to provide valuable feedback. The more coaches analyze, the more they can verify the strengths and challenges that need to be addressed.

\section{Conclusion}

Based on our objectives, applied methods and obtained results, we conclude that weight categories have different performance characteristics which should be considered for training prescription. In summary, it was noted that the half lightweight category showed higher approach attempts, higher pause time in groundwork combat and lower left Tae-sabaki. The lightweight group presented lower gripping attempt frequencies and higher arm and leg lever scored values, while the extra lightweight category presented lower right and left back sleeve grip frequencies. The heavyweight group presented lower frequency of total attack. Biomechanical levers used during attacks have to be considered during training, considering that female extra lightweight judokas demonstrated a higher frequency of techniques with the arm and leg lever scored than half lightweight, while half lightweight athletes demonstrated a higher frequency of techniques with a waist lever variable scored than the lightweight group. Finally, half middleweight judokas demonstrated a higher frequency of techniques with the maleolo lever than the half heavyweight and heavyweight categories.

\section{Acknowledgements}

Fundação de Amparo à Pesquisa do Rio de Janeiro - FAPERJ Grant E-26/202.810/2019 (247397).

\section{References}

Bartlett R. Performance analysis: can bringing together biomechanics and notational analysis benefit coaches? Int J Perform Anal Sport, 2001; 1(1): 122-126

Brito CJ, Miarka B, Durana ALD, Fukuda DH. Home Advantage in Judo: Analysis by the Combat Phase, Penalties and the Type of Attack. J Hum Kinet, 2017; 57(1): 213-220

Calmet M, Miarka B, Franchini E. Modeling of grasps in judo contests. Int J Perform Anal Sport, 2010; 10(3): $229-240$ 
Del Vecchio F, Dimare M, Franchini E, Schaun G. Physical fitness and maximum number of all-out hikidashi uchi-komi in judo practitioners. Med Del Sport, 2014; 67: 383-396

Marcon G, Franchini E, Jardim JR, Barros Neto TL. Structural analysis of action and time in sports: judo. J Quant Anal Sports, 2010; 6(4): 1-13

Miarka B, Brito CJ, Amtmann J, Córdova C, Bello FD, Camey S. Suggestions for Judo Training with Pacing Strategy and Decision Making by Judo Championship Phases. J Hum Kinet, 2018; 15(64): 219-232

Miarka B, Brito CJ, Dal Bello F, Amtmann J. Motor actions and spatiotemporal changes by weight divisions of mixed martial arts: applications for training. Hum Mov Sci, 2017; 55: 73-80

Miarka B, Cury R, Julianetti R, Battazza R, Julio UF, Calmet M, Franchini E. A comparison of time-motion and technical-tactical variables between age groups of female judo matches. J Sport Sci, 2014; 32(16): 1529-1538

Miarka B, Del Vecchio FB, Julianetti R, Cury R, Camey S, Franchini, E. Time-motion and tactical analysis of Olympic judo fighters. Int J Perform Anal Sport, 2016; 16(1): 133-142

Miarka B, Fukuda, DH, Del Vecchio FB, Franchini E. Discriminant analysis of technical-tactical actions in high-level judo athletes. Int J Perform Anal Sport, 2016; 16(1): 30-39

Miarka B, Fukuda DH, Heinisch HD, Battazza R, Del Vecchio FB, Camey S, Franchini E. Time-motion analysis and Decision Making in Female Judo Athletes during Victory or Defeat at Olympic and NonOlympic Events: Are Combat Actions Really Unpredictable? Int J Perform Anal Sport, 2016; 16(2): 442463

Miarka B, Hayashida CR, Julio UF, Calmet M, Franchini E. Objectivity of FRAMI-software for judo match analysis. Int J Perf Anal Sport, 2011; 11(2): 254-266

Miarka B, Panissa VLG, Julio UF, Del Vecchio FB, Calmet M, Franchini E. A comparison of time-motion performance between age groups in judo matches. J Sport Sci, 2012; 30(9): 899-905

Miarka B, Sterkowicz-Przybycien K, Fukuda DH. Evaluation of Sex-Specific Movement Patterns in Judo Using Probabilistic Neural Networks. Mot Control, 2017; 21(4): 390-412

Muddle TWD, Fukuda DH, Wang R, Riffe JJ, Church DD, Beyer KS, Hoffman JR, Stout JR. Effects of a 10Week Introductory Judo Course on Postural Control During a Bilateral Reactionary Gripping Task. Mot Control, 2017; 21(4): 373-389

Sacripanti A. Biomechanical revision of the principles of Dr. Jigoro Kano's judo kodokan. Med Del Sport, 2012; 65(2): 265-281

Sterkowicz-Przybycien K, Miarka B, Fukuda DH. Sex and weight category differences in time-motion analysis of elite judo athletes: Implications for assessment and training. J Strength Cond Res, 2017; 31(3): $817-825$

Sterkowicz S, Sacripanti A, Sterkowicz-Przybycien K. Techniques frequently used during London Olympic judo tournaments: a biomechanical approach. Arch Budo, 2013; 1(9): 1-13

\section{Corresponding author:}

\section{Bianca Miarka}

Av. Carlos Chagas Filho, 540 - Cidade Universitária da Universidade Federal do Rio de Janeiro, Rio de Janeiro - RJ, 21941-599

Telephone: +55(21) 3938-6849

E-mail: miarkasport@hotmail.com 